Article

\title{
Effect of Salinity and Nitrogen Sources on the Leaf Quality, Biomass, and Metabolic Responses of Two Ecotypes of Portulaca oleracea
}

\author{
Maria Camalle ${ }^{1}$, Dominic Standing ${ }^{1, *}$, Mohammed Jitan ${ }^{2}$, Rana Muhaisen ${ }^{2}$, Nidal Bader ${ }^{2}$, \\ Majed Bsoul $^{2}$, Yvonne Ventura ${ }^{1}$, Aigerim Soltabayeva ${ }^{1}$ and Moshe Sagi ${ }^{1}{ }^{\mathbb{D}}$ \\ 1 French Associates Institute for Agricultural and Biotechnology of Drylands, Blaustein Institutes for Desert \\ Research, Sede Boqer Campus, Ben-Gurion University of the Negev, P.O. Box 653, Beer Sheva 84105, Israel; \\ camallec@post.bgu.ac.il (M.C.); yventura@bgu.ac.il (Y.V.); aigerim.soltabayeva@nu.edu.kz (A.S.); \\ gizi@bgu.ac.il (M.S.) \\ 2 National Centre for Agricultural Research and Extension (NARC), Water Management and Environmental \\ Program, Baqa'a 19381, Jordan; majitan@yahoo.com (M.J.); ranaomuhaisen@yahoo.com (R.M.); \\ nbadr55@yahoo.com (N.B.); bsoulmajed@yahoo.com (M.B.) \\ * Correspondence: standing@bgu.ac.il
}

Received: 5 April 2020; Accepted: 28 April 2020; Published: 6 May 2020

\begin{abstract}
Halophytic plants are, by definition, well adapted to saline soils. However, even halophytes can face nutritional imbalance and the accumulation of high levels of compounds such as oxalic acid (OA), and nitrate $\left(\mathrm{NO}_{3}{ }^{-}\right)$. These compounds compromise the potential nutritional health benefits associated with salt-tolerant plants such as Portulaca oleracea or Purslane. Purslane has long been known to be a highly nutritious leafy vegetable particularly with respect to high levels of omega-3 fatty acids. Thus, preventing the accumulation of non-nutritional compounds will allow plants to be grown in saline conditions as crops. Two ecotypes (ET and RN) of Portulaca oleracea plants were grown under growth room conditions with two levels of salinity $(0,50 \mathrm{mM} \mathrm{NaCl})$ and three ratios of nitrate: ammonium $\left(0: 100 \% ; 33: 66 \% ; 25: 75 \% \mathrm{NO}_{3}{ }^{-}: \mathrm{NH}_{4}{ }^{+}\right)$. The results show that both ecotypes, when exposed to elevated $\mathrm{NO}_{3}{ }^{-}$, showed severe leaf chlorosis, high levels of $\mathrm{OA}$, citric acid, and malic acid. Compared to ecotype $\mathrm{RN}$, ecotype ET, exposed to elevated $\mathrm{NH}_{4}{ }^{+}$concentrations $(33 \%$ and $75 \%$ ) and $50 \mathrm{mM} \mathrm{NaCl}$, displayed a marked reduction in OA content, increased total chlorophyll and carotenoid contents, crude protein content, total fatty acid (TFA) and $\alpha$-Linolenic acid (ALA), enhancing leaf quality. This opens the potential to grow high biomass, low OA P. oleracae crops. Lastly, our experiments suggest that ecotype ET copes with saline conditions and elevated $\mathrm{NH}_{4}{ }^{+}$through shifts in leaf metabolites.
\end{abstract}

Keywords: halophyte; salt tolerance; N-nutrition; purslane; oxalic acid; ammonium nutrition

\section{Introduction}

Soil salinity is increasing around the world, especially in arid and semi-arid ecosystems, due to high evaporation and insufficient ion leaching [1]. An estimated 45 million hectares (20\%) of the soils of irrigated agriculture are affected by salinity [2]. Salinity is a significant abiotic stress that can induce physiological, chemical, and molecular changes in plants [3]. For instance, plant physiological processes such as growth are affected by salinity by inhibiting root growth, which, in turn, limits the uptake of water and nutrients [4], thus leading to water deficiency and nutrient imbalances, causing a shift in the plant growth rate [5]. Therefore, salinized soil and saline water are generally unsuitable for agriculture. However, the use of halophyte species (salt-tolerant plants) could be a promising solution for increasing agricultural production in saline zones [6]. 
Halophyte plants can complete their life cycle in a saline environment rich in sodium chloride or sulphate salts $[7,8]$. There are a few species of halophytes such as Crithmum maritimum, Salicornia spp., Aster tripolium, and Portulaca oleracea, which have been proposed to be introduced into saline water agriculture (reviewed in [9]). However, the utilization of halophytes for saline agriculture needs careful study because even halophytic plant species can be affected by salinity, for instance, salinity caused iron (Fe) deficiency in Aster tripolium, which leads to leaf chlorosis [10]. On the other hand, under saline conditions, nitrate $\left(\mathrm{NO}_{3}{ }^{-}\right)$uptake is affected due to the antagonistic effect between $\mathrm{Cl} \cdot$ and $\mathrm{NO}_{3}$. [11]. This leads to nitrogen $(\mathrm{N})$ deficiency affecting plant development and yield. Additional $\mathrm{N}$ fertilization can alleviate $\mathrm{N}$ deficiency. However, $\mathrm{N}$ surplus can also increase nitrate content increasing oxalic acid (OA) levels in plants [12-16].

Oxalic acid may play several roles in plants, such as plant protection, tissue support, and heavy metal detoxification. Another vital function is its role in balancing excess inorganic cations $\left(\mathrm{Na}^{+}, \mathrm{K}^{+}\right.$, $\mathrm{Ca}^{2+}$, and $\left.\mathrm{Mg}^{2+}\right)$, over anions $\left(\mathrm{NO}_{3} \cdot \mathrm{Cl} \cdot\right.$, and $\left.\mathrm{SO}_{4}{ }^{2} \cdot\right)[17,18]$. However, high levels of $\mathrm{OA}$ can have adverse health effects in vulnerable people and animals, such as those at risk from kidney stones or low plasma levels of iron and calcium $[13,19]$. It has been reported that P. oleracea accumulates OA under high levels of nitrate [21]. On the other hand, it is well documented that salinity and ammonium can reduce OA content in P. oleracea $[13,14,21]$. Unfortunately, ammonium fertilization leads to decreased biomass production in P. oleracea $[14,20]$, and, also, salinity has a negative effect in terms of visible leaf quality [10]. The study of the combined effects of high ammonium nutrition and salinity will help to understand which mechanism plants use to cope with different and combined stresses because the decrease in biomass caused by ammonium is still not well understood. Understating this mechanism could be a critical point to improve the yield and quality of P. oleracea.

In the current study, we elucidated the salt tolerance mechanism and ammonium affinity of two Portulaca ecotypes grown under three nitrate:ammonium ratios. This study sheds light on the mechanisms that one ecotype (ET) uses to tolerate salinity and high levels of ammonium, with a concomitant reduction in $\mathrm{OA}$, while maintaining biomass production, through a rapid assimilation of ammonium-N into the amino acid pool and sugar alcohols accumulation. This finding suggests that ecotype ET is a good candidate to introduce to the agriculture of saline soils.

\section{Materials and Methods}

The seeds of two ecotypes, named RN and ET, were gifted from the Ramat Negev AgroResearch Centre, Israel (http://www.moprn.org/cgi-webaxy/item?210). All chemicals were obtained from Sigma-Aldrich (Sigma-Aldrich Israel, Rehovot, Israel; https://www.sigmaaldrich.com/israel.html) unless otherwise specified. The seeds of two Israeli P. oleracea ecotypes were used. These were designated as ecotype ET and ecotype RN. Experiments were conducted under growth room conditions at the Ben-Gurion University Sde Boqer Campus, at $27^{\circ} \mathrm{C}, 16: 8 \mathrm{~h}$ light-dark with a photosynthetically active rediation (PAR) level of $150 \mu \mathrm{mol} \mathrm{m} \cdot{ }^{2} \mathrm{~s} \cdot{ }^{1}$. The seeds of two ecotypes (ET and RN) of P. oleracea plants were surface sterilized and germinated in standard 90-mm Petri dishes filled with $0.5 \times$ Murashige-Skoog medium without vitamins (Duchefa Biochemie, Netherlands; https://www.duchefa-biochemie.com/) (MS) $\left(2.15 \mathrm{~g} \mathrm{~L}^{-1}\right)$ in $1 \%$ agar or $0.2 \%$ Gelrite (Duchefa Biochemie, Netherlands; https://www.duchefa-biochemie.com/). The $\mathrm{pH}$ of the medium was adjusted to 5.7 before the addition of Gelrite agar. After germination, two-day-old seedlings (30 seedlings of each ecotype (60 total) per Petri dish), the seedlings were aseptically transplanted to sterile $183 \times 40 \mathrm{~mm}$ Petri dishes containing $200 \mathrm{~mL}$ of autoclaved $0.5 \times \mathrm{MS}$ in $1 \%$ agar or $0.2 \%$ Gelrite, $\mathrm{pH}$ 5.7. Treatments (three replicates per treatment) were a factorial combination of $\mathrm{NO}_{3}{ }^{-}: \mathrm{NH}_{4}{ }^{+}$ratios (100:0, 66:33 and $25: 75)$, and two levels of salinity $(0,50 \mathrm{mM} \mathrm{NaCl})$, chosen based on the results of previous studies (data not shown). 


\subsection{Biomass}

Nineteen days after the treatment onset, the plants were harvested and separated into shoots and roots for fresh weight determination. The weights of the 30 fresh shoots were determined immediately, and the shoots were dried at $70{ }^{\circ} \mathrm{C}$ for $72 \mathrm{~h}$. The dry biomass production was expressed as mg dry weight per shoot (DW mg shoot $\left.{ }^{1}\right)$. Shoots for biochemicals analysis were immediately frozen in liquid nitrogen and stored at $-80^{\circ} \mathrm{C}$ until required for analyses.

\subsection{Measurement of Total Chlorophyll, Total Carotenoids, and Protein Content}

Total chlorophyll was extracted from $20 \mathrm{mg}$ of the youngest leaves of three replicates per treatment. The samples were placed in $0.5 \mathrm{~mL}$ of $80 \%$ ethanol and incubated in the dark for $48 \mathrm{~h}$ at $4{ }^{\circ} \mathrm{C}$. The extracts were centrifuged at $18,400 \times g$ for $15 \mathrm{~min}$ and the supernatant collected. Then, the extracts were centrifuged for a further $15 \mathrm{~min}$. Chlorophyll content was measured in 200- $\mu \mathrm{L}$ samples with a spectrophotometer at 649, 665, and $652 \mathrm{~nm}$ (Epoch Microplate Spectrophotometer, BioTek) with Gen5 2.05 software. The total carotenoids were measured at $470 \mathrm{~nm}$ using the same sample. The values obtained from chlorophyll $a, b$, were used to calculate the total chlorophyll using the Wintermans and de Mots equation [22]. The total chlorophyll concentration was expressed as $\mathrm{mg}$ total chlorophyll g. ${ }^{1}$ fresh weight (FW). Total carotenoids were expressed as mg total carotenoids g. ${ }^{1} \mathrm{FW}$. The extraction for protein content was performed according to Elavarthi and Martin (2010). Approximately $100 \mathrm{mg}$ of fresh tissue leaf was ground to a fine powder in liquid nitrogen using a mortar and pestle, and $1 \mathrm{~mL}$ of $200 \mathrm{mM}$ potassium phosphate buffer $(\mathrm{pH} 7.8)$ containing $0.1 \mathrm{mM}$ EDTA and $4 \% \mathrm{w} / \mathrm{v}$ polyvinylpyrrolidone was added. The samples were centrifuged at $18,400 \times g$ for $20 \mathrm{~min}$ at $4{ }^{\circ} \mathrm{C}$, and the supernatant was collected. Protein content was determined using the Bradford assay [23] adapted for microplate reader using bovine serum albumin (BSA) as the protein standard. Total protein content was measured in $200 \mu \mathrm{L}$ samples with a spectrophotometer at $595 \mathrm{~nm}$ (Epoch Microplate Spectrophotometer, BioTek) with Gen5 2.05 software.

\subsection{Metabolite Analysis by GC-MS (Gas Chromatography-Mass Spectrometry)}

Lyophilized leaves $(20 \mathrm{mg}$ ) of each sample were homogenized in $2 \mathrm{~mL}$ Eppendorf tubes with three 5-mm tungsten carbide beads for $10 \mathrm{~s}$. The extraction solution was made following Lisec [24]. One thousand $\mathrm{mL}$ pre-chilled reaction mixture contending $\left(25 \mathrm{~mL}\right.$ methanol pre-cooled at $-20^{\circ} \mathrm{C}$ with $380 \mu \mathrm{L}$ of a stock of corticosterone $1 \mathrm{mg} \mathrm{mL} \cdot{ }^{1}$ in HPLC-grade methanol), $10 \mathrm{~mL}$ chloroform and $10 \mathrm{~mL}$ Milli-Q water with $400 \mu \mathrm{L}$ of ribitol (0.2 $\mathrm{mg} \mathrm{mL}^{.1}$ ribitol in Milli-Q water), $200 \mu \mathrm{L}$ sorbitol $6 \mathrm{C}^{13}(0.2 \mathrm{mg}$ $\mathrm{mL} \cdot{ }^{1}$ sorbitol $6 \mathrm{C}^{13}$ in Milli-Q water) and $200 \mu \mathrm{L}$ norleucine $\left(0.2 \mathrm{mg} \mathrm{mL} \cdot{ }^{1}\right.$ norleucine in Milli-Q water) were used as an internal quantitative standard, and the samples were vortexed. Homogenized tissue was incubated for $10 \mathrm{~min}$ at $25^{\circ} \mathrm{C}$ in an orbital shaker. Samples were then sonicated for $10 \mathrm{~min}$ in an ultra-sonication bath at room temperature. After that, the samples were centrifuged at $18,000 \times g$ for $10 \mathrm{~min}$ at $4{ }^{\circ} \mathrm{C}$. After centrifugation, the supernatant was transferred to 2-mL Eppendorf tubes, and $300 \mu \mathrm{L}$ Milli-Q water and $300 \mu \mathrm{L}$ chloroform were added, then vortexed for $10 \mathrm{~s}$; these samples were centrifuged at $18,000 \times g$ for $10 \mathrm{~min}$. After centrifugation, $150 \mu \mathrm{L}$ of the polar phase (methanol and water) of the supernatant was dried under a vacuum for derivatization.

\subsubsection{Derivatization}

N-Methyl-N-(trimethylsilyl) trifluoroacetamide (MSTFA) diluted in chloroform to a final concentration of $0.4 \mathrm{~mL} \mathrm{~mL}^{-1}$ and methoxyamine hydrochloride dissolved in pyridine $\left(20 \mathrm{mg} \mathrm{mL}^{-1}\right.$ MSTFA in pyridine) were used for derivatization. A total of $40 \mu \mathrm{L}$ of methoxyamine hydrochloride was added to the samples, and the samples were shaken for $2 \mathrm{~h}$ at $37^{\circ} \mathrm{C}$. Then, a mixture of $70 \mu \mathrm{L}$ MSTFA and $7 \mu \mathrm{L}$ of Alkan were added to the samples. Samples were shaken again for $30 \mathrm{~min}$ at $37^{\circ} \mathrm{C}$. Aliquots were then transferred into glass vials suitable for GM-CS analysis. The samples were used to determine free organic acids and metabolites in the leaf tissue following Lisec [24]. 


\subsubsection{Lipid Analysis}

Total polar lipids were quantified following Brychkova et al. [25] by Trace GC Ultra (Thermo Fisher Scientific, Massachusetts, USA; https:/www.thermofisher.com/il/en/home.html) as the methyl esters of the constituent fatty acids after 2-D thin-layer chromatography. The first dimension was chlorophorm:methanol:water (Milli-Q) $(65: 25: 4, \mathrm{v} / \mathrm{v} / \mathrm{v})$ followed by the second dimension of chlorophorm:methanol:ammonium hydroxide: isopropylamine (65:35:5:0.5, v/v/v/v). Visualization was performed under ultraviolet.

\subsubsection{GC-MS Conditions and Analysis}

The GC-MS system consisted of an AS 3000 autosampler, a Trace GC Ultra gas chromatograph, and a DSQII quadrupole mass spectrometer. GC was performed on a 30-m VF-5ms column with $0.25-\mathrm{mm}$ i.d. and 0.25-m film thickness $+10 \mathrm{~m}$ EZ-Guard (Agilent, California, USA; https://www.agilent.com/). A 1- $\mu \mathrm{L}$ sample was injected into an injection port liner (Split liner with Wool, Restek, USA). Programmed Temperature Vaporization (PTV) injection temperature was from 60 to $300{ }^{\circ} \mathrm{C}$ in $14.5^{\circ} \mathrm{C} \mathrm{s}^{-1}$, the transfer line was $300^{\circ} \mathrm{C}$, and the ion source adjusted to $250^{\circ} \mathrm{C}$. The carrier gas used was helium set

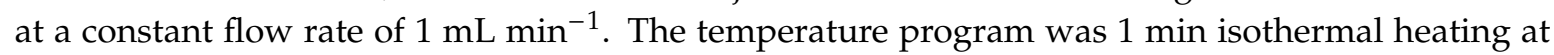
$70{ }^{\circ} \mathrm{C}$, followed by a $1{ }^{\circ} \mathrm{C} \mathrm{min}-1$ oven temperature ramp to $76{ }^{\circ} \mathrm{C}$, followed by a $6{ }^{\circ} \mathrm{C} \mathrm{min}-1$ oven temperature ramp to $350{ }^{\circ} \mathrm{C}$, and a final $5 \mathrm{~min}$ of heating at $350^{\circ} \mathrm{C}$. The mass spectrometer was tuned according to the manufacturer's recommendations using tris-(perfluorobutyl)-amine (CF43). Mass spectra were recorded at 8 scans per second with a mass-to-charge ratio of 70 to 700 scanning range with electron energy of $70 \mathrm{eV}$. Spectral searching utilized the National Institute of Standards and Technology (NIST, Gaithersburg, USA; https://www.nist.gov/) algorithm incorporated in the Xcalibur ${ }^{\circledR}$ data system (version 2.0.7) against Retention Index (RI) libraries downloadable from the Max-Planck Institute for Plant Physiology in Golm, Germany (http://www.mpimp-golm.mpg.de/mms-library/).

\subsubsection{Statistical Analysis}

The statistical analyses of the data set consisted of two categorical variables (Nitrate:ammonium ratios, with three levels, 100:0, 66:33 and 25:75, respectively, and salt two levels $(0,50 \mathrm{mM} \mathrm{NaCl})$ ), and 42 continuous metabolomic variables identified by libraries downloadable from the Max-Planck Institute for Plant Physiology in Golm, Germany (http://www.mpimp-golm.mpg.de/mms-library). JMP13 (SAS Institute Inc., USA; https://www.sas.com/en_us/software/stat.html) was used to test for differences between nitrogen ratios and salinity, and the data were subjected to a two-way ANOVA for all the parameters measured. Where ANOVA indicated significant differences, means were compared by the Tukey-Kramer HSD test. A data set of the two ecotypes was analysed by principal component analysis (PCA) using R version 3.6.1 [26] to determine variability among treatments. Hierarchical cluster analysis was calculated among the metabolites. Metabolite spectra data were normalized by the internal standard sorbitol $6 \mathrm{C}^{13}$ as well as by the median of each metabolite across all samples, and, finally, the resulting values transformed to its $\log _{2}$ for the PCA and heat map. The heat map with the Euclidian distance was performed with the "ComplexHeatmap" package [27]. The PCA was performed using "factoextra" package [28].

\section{Results}

\subsection{Effect of Nitrogen Forms and Salinity on the Leave Quality of Portulaca Plants and Biomass Production}

High ammonium and salinity affected leaf quality in Ecopyte RN yet not in ecotype ET. At harvest, plants of ecopyte $\mathrm{RN}$ exposed to $75 \%$ and $66 \% \mathrm{NO}_{3}{ }^{-}$ammonium under saline conditions showed curling leaves, necrosis on the edges of the leaves, leaf chlorosis and necrotic spotting. This effect was less notable in plants exposed to $100 \% \mathrm{NO}_{3}{ }^{-}$with the exception of leaf chlorosis, which was drastically affected. 
Different ratios of nitrate:ammonium significantly affected total leaf chlorophyll and total carotenoids content. Two-way ANOVA confirmed that there was a highly significant $(P<0.001)$ effect of the nitrate to ammonium ratios, salinity, and their interaction on total chlorophyll and total carotenoid accumulation in both ecotypes (Figure 1Aa,Ba). The higher levels of total chlorophyll were found in plants grown either with $33 \%$ or $75 \%$ of ammonium without salinity compared with plants exposed to elevated $\mathrm{NO}_{3}{ }^{-}$in both ecotypes (Figure $1 \mathrm{Aa}, \mathrm{Ba}$ ). Salinity in ammonium-grown plants lead to a drop of total chlorophyll; however, the levels of the total chlorophyll observed were still higher compared to the plants exposed to $100 \% \mathrm{NO}_{3}{ }^{-}$(Figure $1 \mathrm{Aa}$ ). We observed a similar effect on the total carotenoids levels. The highest levels were found either with $33 \%$ or $75 \%$ of ammonium without salinity in both ecotypes (Figure $1 \mathrm{Ab}, \mathrm{Bb}$ ). Salinity in ammonium-grown plants slightly affected total carotenoids, although the levels found under salinity conditions in ammonium-treated plants were higher than the plants exposed to $100 \% \mathrm{NO}_{3}{ }^{-}$(Figure $1 \mathrm{Ab}, \mathrm{Bb}$ ). Ammonium nutrition had a positive effect in terms of protein content. As was confirmed by two-way ANOVA, the protein content was significantly $(P<0.001)$ affected by the nitrate to ammonium ratio, salinity, and their interaction in both ecotypes (Figure $1 \mathrm{Ac}, \mathrm{Bc}$ ). The highest levels of the protein content were found in plants exposed to high levels of ammonium nutrition in both ecotypes (Figure $1 \mathrm{Ac}, \mathrm{Bc}$ ).

Plants exposed to high levels of ammonium and in saline conditions showed a decrease in protein content, but the levels found there were higher compared to the plants exposed to $100 \% \mathrm{NO}_{3}^{-}$ nutrition (Figure 1Ac). Significant differences $(P<0.05$ in the levels of the $\alpha$-Linolenic acid (ALA) (Figure $1 \mathrm{Ad}, \mathrm{Bd}$ ) and total fatty acid (TFA) (Figure 1Ae,Be) were found in both ecotypes. The highest levels of ammonium in ecotype ET grown under saline conditions induced the up-regulation of TFA and ALA (Figure 1Ad,Ae). Lower levels of these compounds were found in plants exposed to high levels on ammonium without salinity and in plants exposed to $100 \% \mathrm{NO}_{3}{ }^{-}$with salinity (Figure $1 \mathrm{Ad}, \mathrm{Ae}$ ). In ecotype RN, the levels of TFA and ALA were affected by salinity in plants treated either with $100 \%$ or $66 \% \mathrm{NO}_{3}{ }^{-}$(Figure $1 \mathrm{Bd}, \mathrm{Be}$ ).

In contrast to ecotype ET, the TFA and ALA levels in RN were not affected by high levels of ammonium (Figure 1Bd). OA was highly significantly $(P<0.001)$ affected by nitrate to ammonium ratios, and there was also a significant effect $(P<0.01)$ of salinity on OA content (Figure 1Af,Bf). The combination of the salinity and nitrogen forms was not significant $(\mathrm{P}>0.05)$ in terms of OA accumulation (Figure 1Af). The lowest level of OA was observed in plants exposed to 75\% of ammonium while the highest levels were found in plants exposed to $100 \% \mathrm{NO}_{3}{ }^{-}$in both ecotypes (Figure 1Af,Bf). Salinity decreased levels of OA in plants grown either with $33 \%$ or $75 \%$ ammonium compared with plants grown with $100 \% \mathrm{NO}_{3}{ }^{-}$in both ecotypes (Figure 1Af,Bf). Shoot $\mathrm{FW}$ was significantly $(P<0.001)$ affected by nitrogen form and salinity. Moreover, a significant $(P<0.01)$ effect of the interaction of salinity and nitrogen form was observed in both ecotypes (Figure 1Ag,Bg). The highest shoot FW accumulation was found in plants exposed to $100 \% \mathrm{NO}_{3}{ }^{-}$under saline and non-saline conditions (Figure $1 \mathrm{Ag}, \mathrm{Bg}$ ). Ammonium affects shoot FW, where the combination of ammonium with salinity enhanced shoot FW in ecotype ET (Figure 1Ag); this effect was not observed in ecotype RN (Figure 1Bg). 
A: ecotype ET
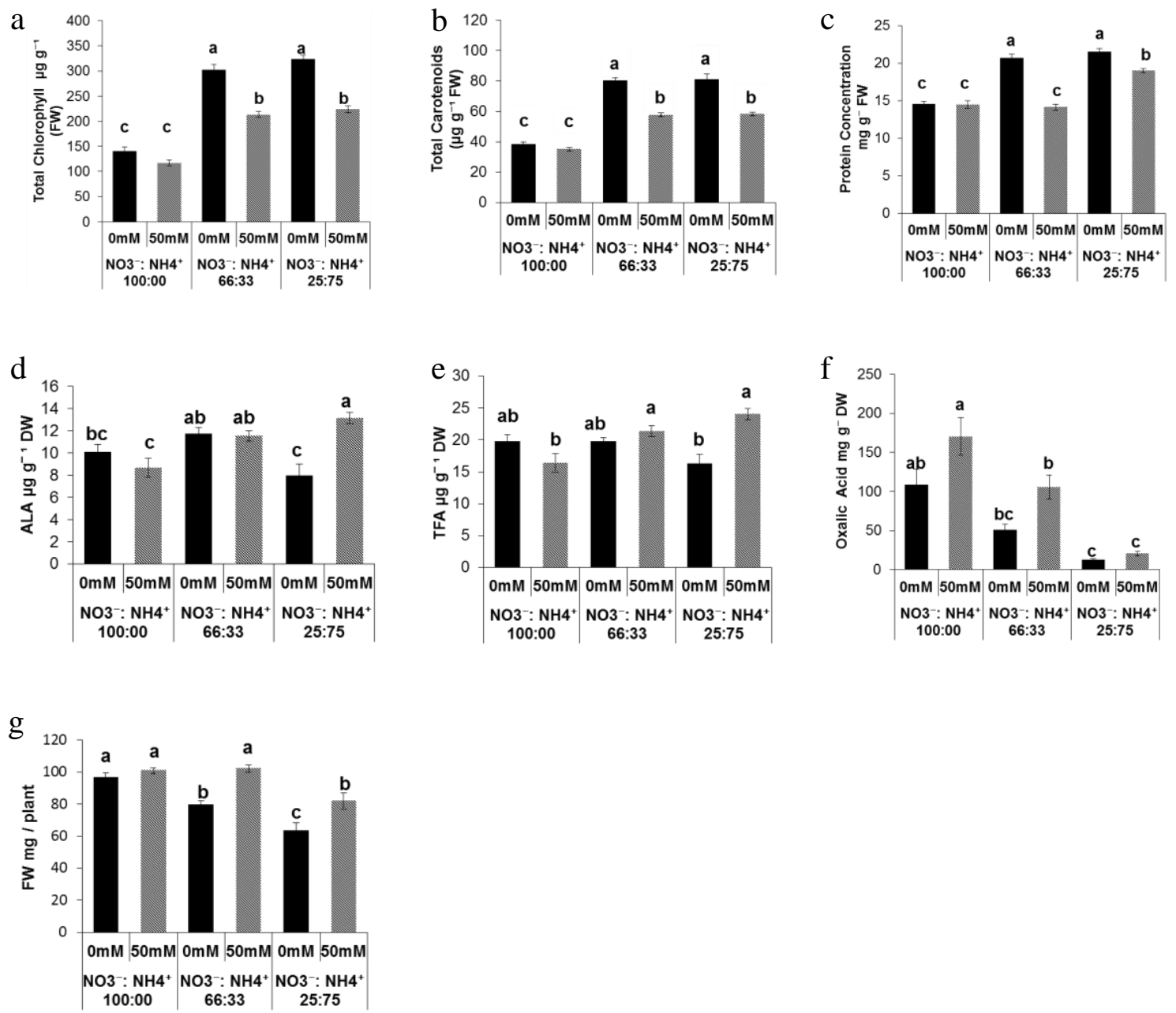

B: ecotype RN
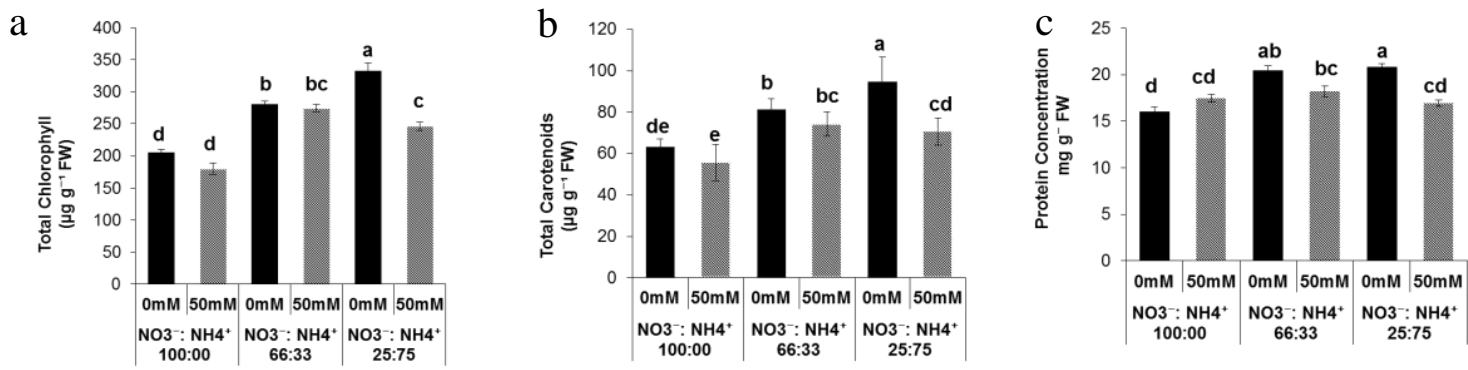

Figure 1. Cont. 

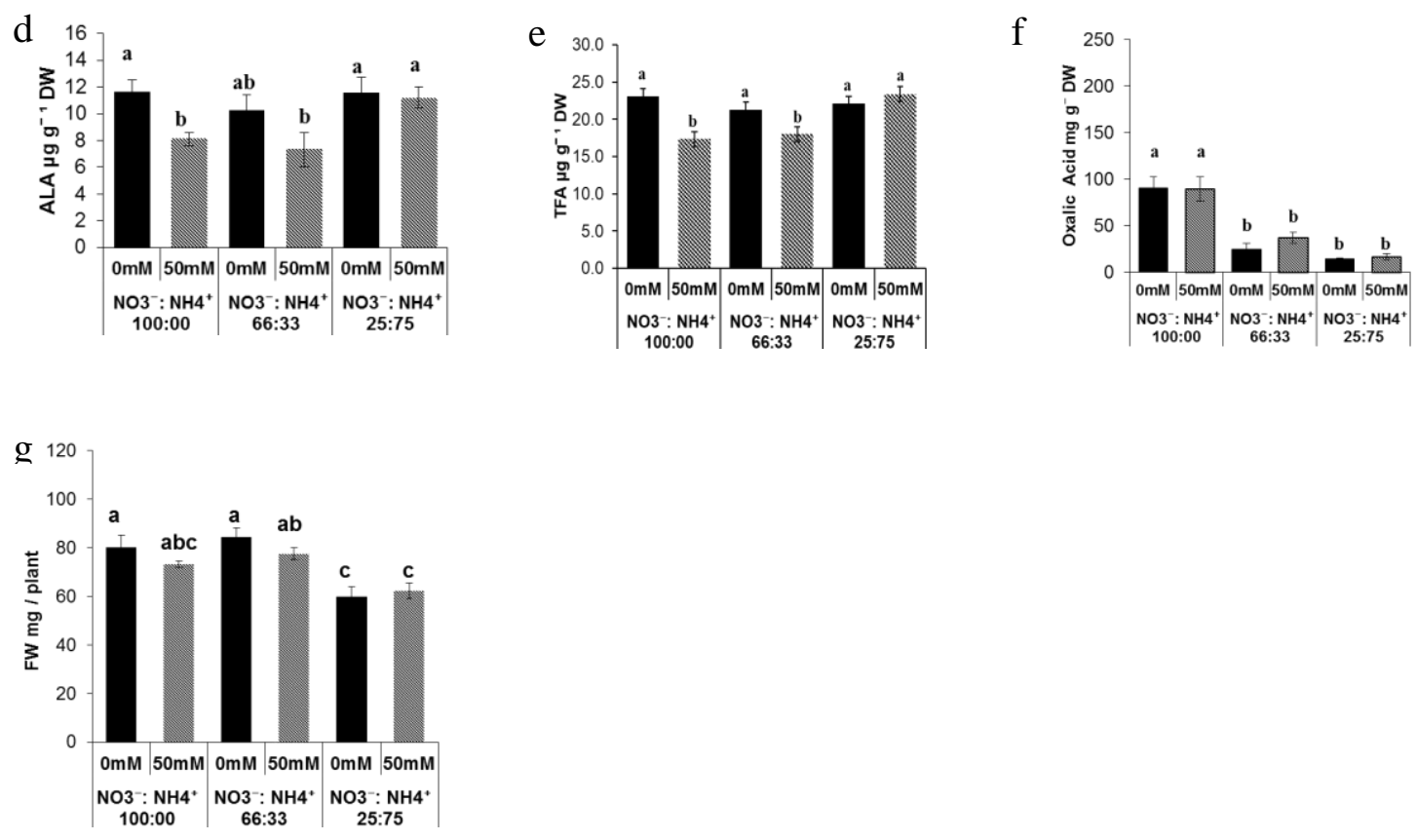

Figure 1. Effect of the nitrate to ammonium ratio $(100: 00,66: 33,25: 75)$ and salinity $(0,50 \mathrm{mM})$ on the leaf quality and biomass accumulation of P. oleracea leaves ecotypes ET (A) and RN (B). The values are means $\pm \mathrm{SE}(n=6)$. Bars with different letters are significantly different between treatments, $P \leq 0.05$, as determined by Tukey-Kramer HSD.

\subsection{Sugar Metabolite Changes in Response to Salt and Nitrogen Forms}

The metabolomic profiling revealed leaf metabolomic variation between two ecopytes in response to the three nitrogen forms and salt stress. The principal component analysis (PCA) of leaf metabolites revealed a clear separation between nitrogen forms in both ecotypes (Supplmentary Figures S1A and S2A). In the ecotype, ET, the first component explained $83.6 \%$ of the total metabolic variation among nitrate forms, and the second component separated salt stress plants from those control plants explained $5 \%$ of the total metabolic variation (Supplmentary Figure S2A). Contrastingly, in the ecopyte $\mathrm{RN}$, the first component, $65.4 \%$ of the total metabolic variation between nitrogen forms and the second component separated salt stress plants from the control plant. (Supplmentary Figure S2A). The relative abundances of the metabolites that were significantly different between the treatments are presented below.

\subsection{Sugar Metabolite Changes in Response to Salt and Nitrogen Forms}

In response to salt stress, plants accumulated sugars; the metabolomics profiling revealed that salt stress leads to sugar accumulation in both ecopytes regardless of the nitrogen forms used (Supplmentary Figures S1A and S2A). Two-way ANOVA confirmed that there was a highly significant $(P<0.001)$ effect of the nitrate to ammonium ratios, salinity, and their interaction on fructose and galactinol accumulation (Figure 2Aa,Ac). Salt stress enhanced the fructose content of ecotype RN plants grown with $75 \%$ of ammonium, while, in ecopyte ET, these levels were higher in $75 \%$-ammonium-grown plants (Figure 2Aa, $\mathrm{Ba}$ ) and the lowest levels in plants exposed to $100 \% \mathrm{NO}_{3}{ }^{-}$(Figure 2Aa). Salinity rose leaves galactinol content of ecotype ET; however, this level was low in $66 \% \mathrm{NO}_{3}{ }^{-}$plants. Contrastingly, in ecotype $\mathrm{RN}$, salinity increased leaf galactinol content, but nitrogen form had no effect (Figure $2 \mathrm{Bb}$ ). The levels of raffinose, pinitol, and ononitol were significantly $(P<0.001)$ affected by salinity and nitrogen form but not by their interaction (Figure 2Ae,Af). The levels of the pinitol and ononitol under saline conditions were approximately the same in the three forms of nitrogen tested, while levels of raffinose were different in plants exposed to $66 \% \mathrm{NO}_{3}{ }^{-}$(Figure $2 \mathrm{Ac}, \mathrm{Ae}, \mathrm{Af}$ ). In ecotype, $\mathrm{RN}$, these sugars 
accumulated in plants exposed to $100 \% \mathrm{NO}_{3}{ }^{-}$under saline conditions (Figure 2Be,Bf). Raffinose levels were lower only in plants exposed to $100 \%$ and $66 \% \mathrm{NO}_{3}{ }^{-}$without salinity (Figure 2Bc). Myoinositol levels were affected by salinity but not nitrogen form in ecotype ET, but in ecotype, RN was affected by both salinity and nitrogen form (Figure 2Ad,Bd). The highest level of myoinositol in ecotype ET was found in plants exposed to $75 \%$ ammonium under saline conditions and the lowest levels in plants exposed to $66 \% \mathrm{NO}_{3}{ }^{-}$without salinity (Figure 2Ad). A similar effect was observed in ecotype $\mathrm{RN}$, wherein the lowest levels were found in both levels of $\mathrm{NO}_{3}{ }^{-}(100 \%$ and $66 \%)$ (Figure 2Bd). These results suggested that Portulaca plants alleviate salt stress by sugar accumulation, which probably helps to keep the cellular osmotic balance.

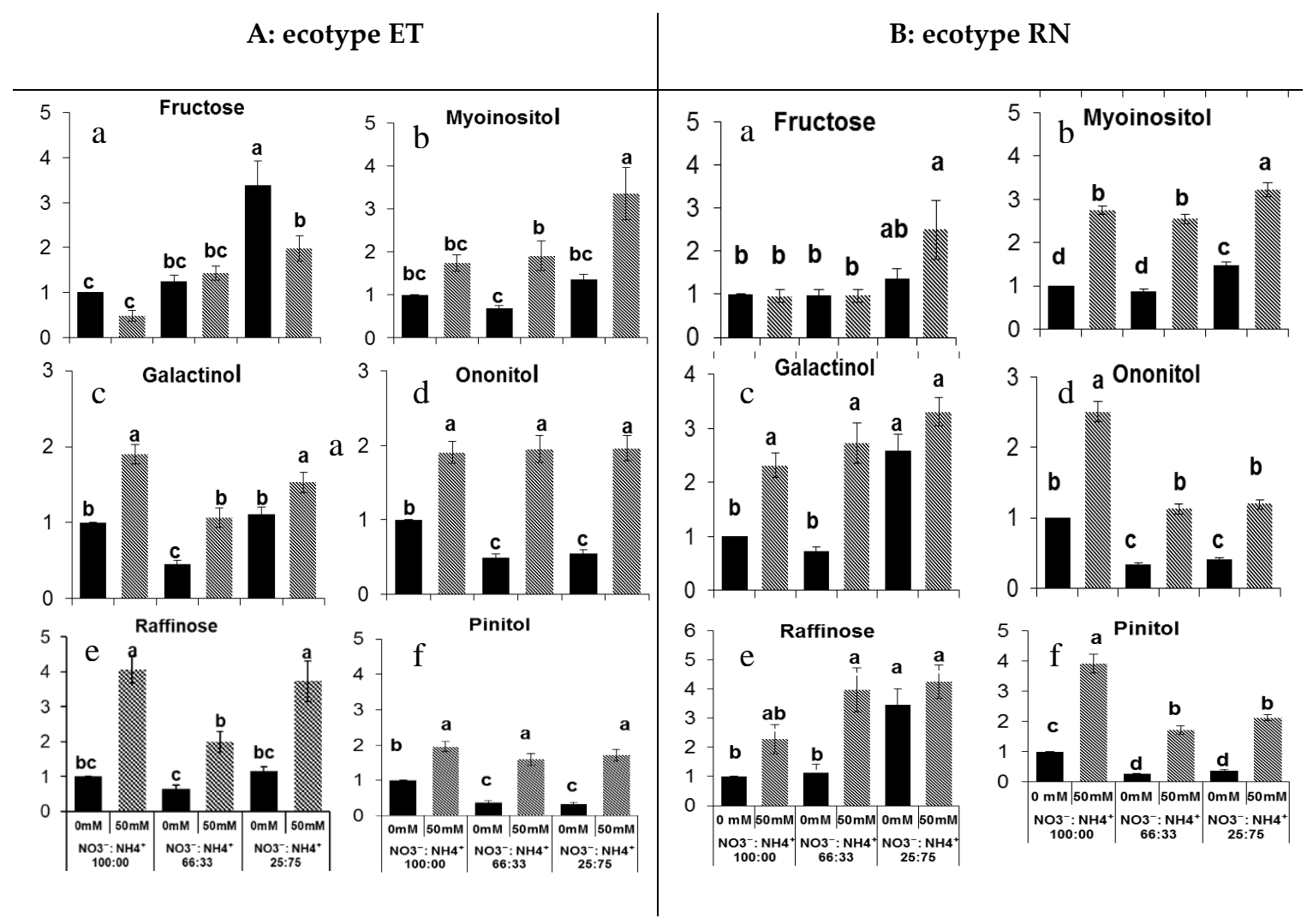

Figure 2. Effect of the nitrate to ammonium ratio $(100: 00,66: 33,25: 75)$ and salinity $(0,50 \mathrm{mM})$ on the sugar accumulation of $P$. oleracea leaves ecotypes ET (A) and RN (B). The values are means \pm SE $(n=6)$. Bars with different letters are significantly different between treatments, $P \leq 0.05$, as determined by Tukey-Kramer HSD.

\subsection{Free Amino Acid Metabolite Changes in Response to Salt and Nitrogen Forms}

Leaf metabolomic profiling showed that the changes in the amino acid profiles in response to nitrogen form and salinity were noticeable in the ammonium-grown plants (Supplmentary Figures S1A and S2A). The 11 amino acids identified here were significantly $(P<0.001)$ affected by nitrogen form. Under high ammonium nutrition, some amino acids, including glutamate, glycine, ornithine, phenylalanine, proline, serine, and tyramine, showed increased accumulation (Figure 3). Aspartate and phenylalanine metabolism was enhanced by salinity $(P<0.001)$ (Figure $3 b, h)$. Ornithine was the most abundant amino acid found in plants exposed to $75 \%$ ammonium under saline conditions wherein the enhancement was 10-fold more than in plants exposed elevated $\mathrm{NO}_{3}{ }^{-}$(Figure 3g). Urea level also was affected by nitrogen form but not by salinity. In ecotype $\mathrm{RN}$, the same 11 amino acids were detected (Figure 4). However, the relative abundances were lower compared with ecotype ET. The levels of glutamate, glycine, leucine, ornithine, phenylalanine, proline, serine, and tyramine were significantly $(P<0.001)$ affected by nitrogen form. In this ecotype, ornithine was also the most abundant amino acid 
detected, although it was lower compared to ecotype ET. In addition, organic acids of the tricarboxylic acid (TCA) cycle were detected. Quantification was made using the linear calibration curves of analytical standards derivatized in the same way as the leaf samples. In ecotype ET malic acid, citric acid and ascorbic acid contents were elevated in plants exposed to $100 \% \mathrm{NO}_{3}{ }^{-}$. (Figure $5 \mathrm{Aa}, \mathrm{b}$ ). Salinity leads to the enhancement of citric acid in nitrate-grown plants; this result was directly correlated with the leaf chlorosis observed (Figure 5Aa). Ascorbic acid was significantly $(P<0.001)$ affected by the interaction of salinity with nitrogen forms (Figure 5Ac). The highest levels were found in $66 \% \mathrm{NO}_{3}{ }^{-}$ and ammonium-grown plants under saline conditions (Figure 5Ac). In ecotype RN, this organic acid was also affected by nitrogen forms; the highest levels of these three organic acids were observed in plants exposed to $100 \% \mathrm{NO}_{3}{ }^{-}$(Figure 5B). These results underline that ecopyte ET assimilated ammonium faster into the amino acids pool either under salt and no salt stress conditions, thus avoiding leaf ammonium toxicity.

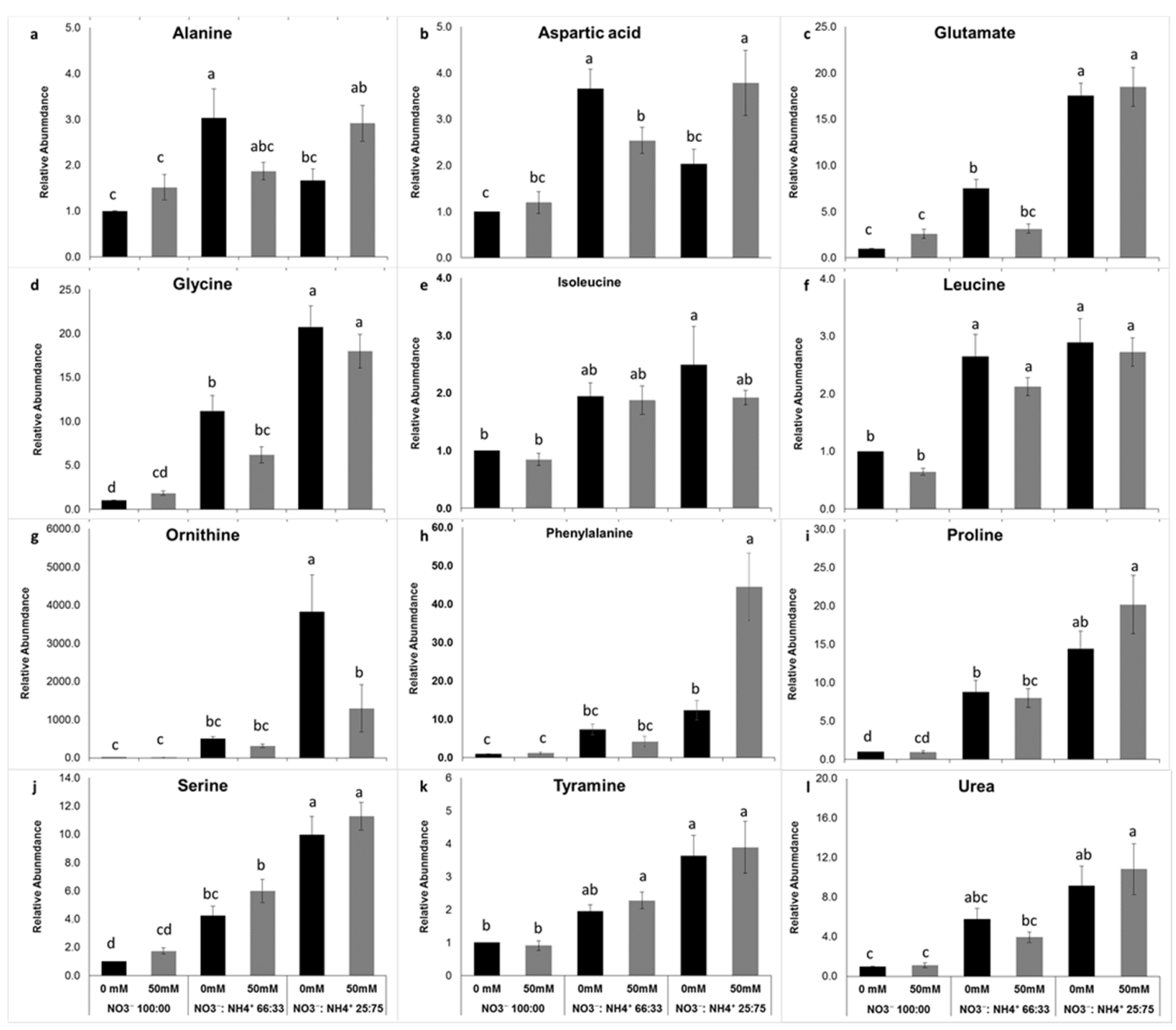

Figure 3. Effect of the nitrate to ammonium ratio (100:00, 66:33, 25:75) and salinity $(0,50 \mathrm{mM})$ on the amino acid accumulation of $P$. oleracea leaves ecotype ET. The values are means \pm SE $(n=6)$. Bars with different letters are significantly different between treatments, $P \leq 0.05$, as determined by Tukey-Kramer HSD. 


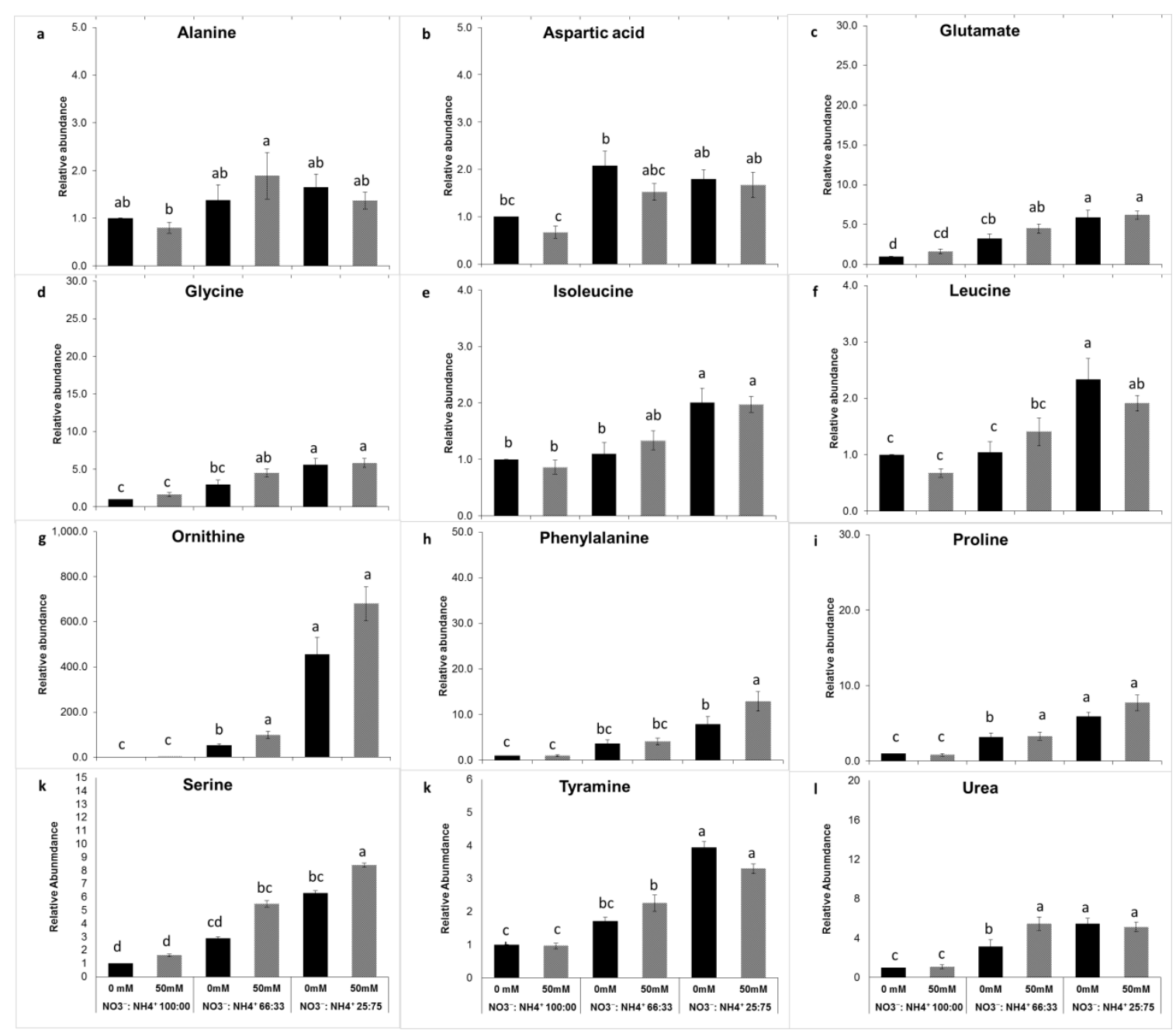

Figure 4. Effect of the nitrate to ammonium ratio $(100: 00,66: 33,25: 75)$ and salinity $(0,50 \mathrm{mM})$ on the amino acid accumulation of $P$. oleracea leaves ecotype RN. The values are means \pm SE $(n=6)$. Bars with different letters are significantly different between treatments, $P \leq 0.05$, as determined by Tukey-Kramer HSD. 
A: ecotype ET
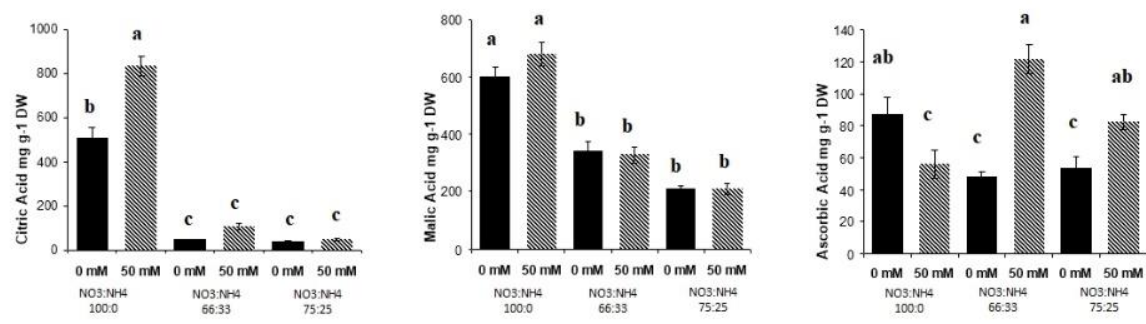

B: ecotype RN
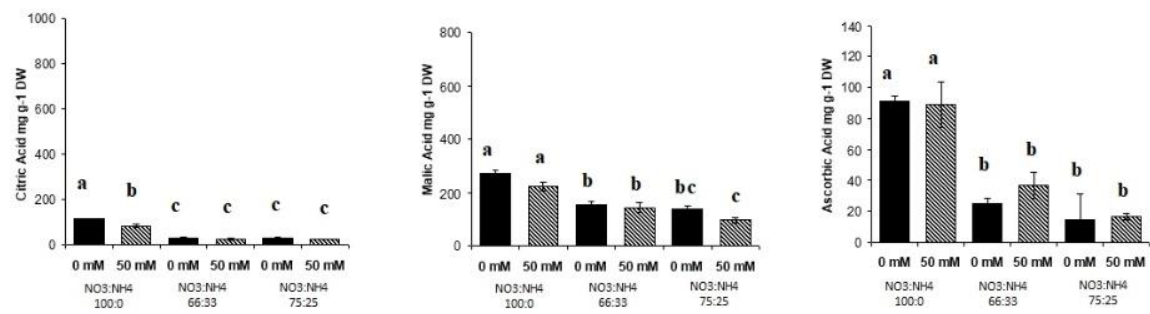

Figure 5. Effect of the nitrate to ammonium ratio $(100: 00,66: 33,25: 75)$ and salinity $(0,50 \mathrm{mM})$ on the organic acid accumulation of $P$. oleracea leaves ecotypes ET (A) and RN (B). The values are means \pm SE $(n=6)$. Bars with different letters are significantly different between treatments, $P \leq 0.05$, as determined by Tukey-Kramer HSD.

\section{Discussion and Conclusion}

P. oleracea plants are well known to accumulate high levels of $\mathrm{NO}_{3}{ }^{-}$and $\mathrm{OA}$, but, although a nutritionally desirable decrease in OA can be achieved by altering the $\mathrm{NO}_{3}{ }^{-}: \mathrm{NH}_{4}{ }^{+}$ratio (in non-saline conditions), it has a negative effect on biomass [14,20]. Our results are in agreement with this. However, applying $75 \%$ ammonium to the growth medium in saline conditions resulted in increased dry weight in ecotype ET. This enhancement suggests that, under saline conditions, ecotype ET can assimilate ammonium faster than ecotype RN, as shown by the increase of the free amino acid pool and fatty acids. Furthermore, $75 \%$ ammonium in both saline and non-saline medium led to increased levels of total chlorophyll, carotenoid, crude protein, ALA, and TFA, enhancing leaf quality while, importantly, having reduced OA levels. The same general effect was found in ecotype RN, but leaf toxicity was observed. When plants were exposed to elevated $\mathrm{NO}_{3}{ }^{-}(100 \%)$ leaf chlorosis, high levels of OA, malic acid, and citric acid were observed in both ecotypes. We assumed that, under ammonium nutrition and a saline environment, ecotype $\mathrm{RN}$ is sensitive to faster $\mathrm{Na}^{+}$uptake, which caused leaf toxicity and leaf senescence [5]. However, the leaf injury exhibited for purslane ecotype RN may also be a response to an excess of ammonium, which may have disrupted cellular homeostasis and increased oxidative stress. This observation highlighted the sensitivity of ecotype $\mathrm{RN}$ to saline and high ammonium environment. The high levels of citric acid-induced leaf chlorosis were observed in both ecotypes, since high levels of citric acid limit Fe translocation [29], inducing leaf chlorosis [30]. On the other hand, the high levels of malic acid found in plants exposed to $100 \% \mathrm{NO}_{3}{ }^{-}$suggest that, under elevated $\mathrm{NO}_{3}{ }^{-}$, P. oleracea biosynthesizes malic acid in order to maintain ion balance over anionic $\mathrm{NO}_{3}{ }^{-}$(data not shown). Malic acid is one of the organic acids that plants accumulate to control osmotic balance [31]. Little is known about $\mathrm{NO}_{3}{ }^{-}: \mathrm{NH}_{4}{ }^{+}$effects on ALA and TFA contents under saline conditions. The accumulation of free amino acids under high levels of ammonium may serve as $\mathrm{N}$ and $C$ sources for metabolic pathways. Fatty acids could play an essential role in plant protection by enhancing protective compounds' transport, such as glycine betaine [32]. Therefore, the application of $75 \%$ ammonium in saline conditions can improve fatty acid production and acts as an energy source improving biomass production. 
To cope with adverse environmental conditions, plants accumulate osmoprotectants to alleviate cellular hyperosmolarity and ion disequilibrium [33]. Sugars and polyols such as ononitol and pinitol act as compatible solutes resulting in increased cellular osmolarity and as scavengers of reactive oxygen species (ROS) [34-36]; these sugars have been associated with drought and salinity tolerance. Ononitol, pinitol, raffinose, and myoinositol, slightly accumulated under saline conditions in both ecotypes. Nevertheless, the accumulation of ononitol and pinitol under saline conditions in ecotype ET were significantly higher at all three nitrate-to-ammonium ratios (100\%:0\%; 66\%:33\%; $25 \%: 75 \%)$, contrasting with ecotype $\mathrm{RN}$ where these sugars were higher only in the plants exposed to elevated $\mathrm{NO}_{3}{ }^{-}$. The current study suggests that the main strategies for tolerating salinity are by the up-accumulation of sugars and polyols. These findings are consistent with the results obtained by [33], where the combined effect of drought and heat leads to increased sugar synthesis.

Halophytes accumulate amino acids in response to salinity and drought [37]. These amino acids, including aspartic acid, phenylalanine, proline, and ornithine, showed an increase under saline conditions in ammonium growth plants in both ecotypes, but the relative abundance was higher in ecotype ET. Ornithine was by far the most abundant non-protein amino acid; this result confirms that the significant non-protein amino acid synthesized under saline conditions is ornithine. It is well known that the decarboxylation of ornithine is the first step for polyamides formation, and polyamides are known as osmoprotective substances [38,39]. The accumulation of this amino acid under saline conditions and high ammonium levels suggests cellular osmotic adjustments to maintain leaf turgidity. The up-regulation of glutamate, glycine, leucine, isoleucine, serine, tyramine, proline and ornithine in ammonium-grown plants suggests a faster assimilation and conversion of ammonium into free amino acids to avoid ammonium toxicity.

Besides sugar and amino acids, the involvement of organic acids in response to osmotic stress has also been demonstrated. Organic acids could play a central role in the regulation of intracellular $\mathrm{pH}$ by accumulating in vacuoles to neutralize excess cations [40]. Indeed, we observed that elevated $\mathrm{NO}_{3}{ }^{-}$ leads to $\mathrm{NO}_{3}{ }^{-}$accumulation (data not shown) inducing malic and citric acid accumulation in both ecotypes. The accumulation of ascorbic acid is recognized as an effective reactive oxygen species (ROS) scavenger [41,42]. The accumulation of ascorbic acid in transgenic potato plants was directly correlated with their ability to withstand abiotic stress [43]. Therefore, a higher accumulation of ascorbic acid in ecotype ET might contribute to ROS scavenging, thus avoiding leaf nitrate toxicity and aiding salt tolerance. In contrast, the higher ascorbic acid accumulation in ecotype $\mathrm{RN}$ was only found in plants exposed to elevated $\mathrm{NO}_{3}{ }^{-}$. We concluded that the damage observed on the leaves of ecotype $\mathrm{RN}$ grown under $33 \%$ and $75 \%$ of ammonium was a result of ROS accumulation due to the suppression of ascorbic acid necessary for the reductive detoxification of ROS molecules.

In terms of crop potential, ammonium fertilization generally results in low OA contents, but this comes at the cost of low biomass production $[14,20]$. Based on the results of these experiments, it can be concluded that the deleterious effect of high levels of $\mathrm{NH}_{4}{ }^{+}$fertilization on biomass production can be minimized by moderate salinity. This effect seems to be correlated to the increased sugar biosynthesis together with high levels of ascorbic acid accumulation, supporting the idea that $\mathrm{NH}_{4}{ }^{+}$under saline conditions reduced the energy requirements of growth. The results show that combined stresses of salinity and high ammonium nutrition cause different results than saline or ammonium individual stresses, as evidenced by enhancing biomass production, TFA, and ascorbic acid accumulation in one ecotype. The current study also showed natural differences between the ecotypes, as shown by ammonium and salinity toxicity in one ecotype (RN), and ammonium affinity together with salt tolerance by another (ecotype ET). Although nitrogen fertilization improves yield, it seems clear that nitrate cannot be used as a sole nitrogen source for Portulaca plants as this affects harms' yield, quality, and the salt-tolerance threshold. Therefore $75 \%$ ammonium is recommended under moderate saline conditions. 
Supplementary Materials: The following are available online at http://www.mdpi.com/2073-4395/10/5/656/s1, the principal component analysis (PCA) and heat map of leaf metabolites in response to salt and nitrogen form for ecotype ET is shown in Figure 1A and for ecotype RN in Figure 2A.

Author Contributions: All authors have read and agreed to the published version of the manuscript. Conceptualization, M.C., D.S., J.M., N.B., M.B., Y.V. and M.S.; Methodology, M.S., Y.V., A.S., M.C. and D.S.; Validation, M.C., D.S., A.S., M.J., R.M., N.B., M.B. and M.S.; Formal Analysis, M.C., A.S. and M.S.; Investigation, M.C. and M.S.; Resources, M.S.; Data Curation: M.C. and M.S.; Writing-Original Draft Preparation, M.C. and M.S.; Writing-Review \& Editing, M.C., D.S., M.J., R.M., N.B., M.B., Y.V., A.S. and M.S.; Visualization, M.C., D.S., M.J., R.M., N.B., M.B. and M.S.; Supervision, D.S., A.S. and M.S.; Project Administration, M.S., M.J. and R.M.; Funding Acquisition, M.S., M.J. and R.M.

Funding: Funding was provided under the MERC Grant No.: TA-MOU-12-M32-004.

Acknowledgments: We thank N. Sikron and I. Khozin-Goldberg for their assistance with leaf metabolite analysis. We also thank S. Srivastava for his technical support. We are grateful to MERC for their funding support of this research.

Conflicts of Interest: The authors declare no conflicts of interest.

\section{References}

1. Chinnusamy, V.; Zhu, J.K. Plant salt tolerance. Topics in current genetics. In Plant Responses to Abiotic Stress; Hirt, K., Shinozaki, H., Eds.; Springer: Berlin/Heidelberg, Germany, 2003; Volume 4, pp. 241-270.

2. FAO. FAO Soils Portal. Available online: http://www.fao.org/soils-portal/soilmanagement/management-ofsome-problem-soils/salt-affected-soils/moreinformation-on-salt-affected-soils/en/ (accessed on 12 October 2016).

3. Tester, M.; Davenport, R. $\mathrm{Na}^{+}$tolerance and $\mathrm{Na}^{+}$transport in higher plants. Ann. Bot. 2003, 91, 503-527. [CrossRef] [PubMed]

4. Neumann, P.M. Inhibition of root growth by salinity stress: Toxicity of an adaptive biophysical response? In Structure and Function of Roots. Development in Plant and Soil Sciences; Baluska, F., Ciamporova, M., Gasparikova, O., Barlow, P.W., Eds.; Kluwer Academic Publishers: Dordrecht, The Netherlands, 1995; pp. 299-304.

5. Munns, R. Comparative physiology of salt and water stress. Plant Cell Environ. J. 2002, 25, 239-250. [CrossRef] [PubMed]

6. Lieth, H.; Moschenko, M.; Lohmann, M.; Koyro, H.-W.; Hamdy, A. Halophyte uses in different climates I. Ecological and ecophysiological studies. In Progress in Biometeorology; Lieth, H., Ed.; Backhuys Publishers: Leiden, The Netherlands, 1999; pp. 158-258.

7. Flowers, T.J.; Hajibagheri, M.A.; Clipson, N.J.W. Halophytes. Quart. Rev. Biol. 1986, 61, 313-337. [CrossRef]

8. Grieve, C.M.; Suarez, D.L. Purslane (Portulaca oleracea L.): A halophytic crop for drainage water reuses systems. Plant Soil 1997, 192, 277-283. [CrossRef]

9. Ventura, Y.; Eshel, A.; Pasternak, D.; Sagi, M. The development of halophyte-based agriculture: Past and present. Ann. Bot. 2015, 115, 529-540. [CrossRef]

10. Ventura, Y.; Myrzabayeva, M.; Alikulov, Z.; Cohen, S.; Shemer, Z.; Sagi, M. The importance of iron supply during repetitive harvesting of Aster tripolium. Funct. Plant Biol. 2013, 40, 968-976. [CrossRef]

11. Feigin, A.; Rylski, I.; Meiri, A.; Shalhevet, J. Response of melon and tomato plants to chloride-nitrate ratios in saline nutrient solutions. J. Plant Nutr. 1987, 10, 1787-1794. [CrossRef]

12. Palaniswamy, U.R.; Bibble, B.B.; McAvoy, R. Effect of nitrate: Ammonium nitrogen ratio on oxalate levels of purslane. In Trends in New Crops and New Uses; Janick, J., Whipkey, A., Eds.; ASHS Press: Alexandria, VA, USA, 2002; pp. 453-455.

13. Fontana, E.; Hoeberechts, J.; Nicole, S.; Cros, V.; Palmegiano, B.G.; Peiretti, G.P. Nitrogen concentration and nitrate/ammonium ratio affect yield and change the oxalic acid concentration and fatty acid profile of purslane (Portulaca oleracea L.) grown in a soilless culture system. J. Sci. Food Agric. 2006, 86, 2417-2424. [CrossRef]

14. Szalai, G.; Dai, N.; Avinoam, D.; Dudai, N.; Barazani, O. Effect of nitrogen source in the fertilizing solution on nutritional quality of three members of the Portulaca oleracea aggregate. J. Sci. Food Agric. 2010, 90, 2039-2045. [CrossRef] 
15. Ahmed, A.K.; Johnson, K.A. The effect of the ammonium:nitrogen ratio, total nitrogen, salinity $(\mathrm{NaCl})$ and calcium on the oxalate levels of Tetragonia tetragonioides Pallas. Kunz. J. Hortic. Sci. Biotechnol. 2000, 75, 533-538. [CrossRef]

16. Zhang, Y.; Xianyong, L.Y.; Zhang, Y.; Zheng, S.J.; Du, S. Effects of nitrogen levels and nitrate/ammonium ratios on oxalate concentrations of different forms in edible parts of spinach. J. Plant Nutr. 2005, 28, 2011-2025. [CrossRef]

17. Libert, B.; Franceschi, V.R. Oxalate in crop plants. J. Agric. Food Chem. 1987, 35, 926-938. [CrossRef]

18. Sagi, M.; Savidov, N.A.; Lvov, N.P.; Lips, S.H. Nitrate reductase and molybdenum cofactor in annual ryegrass as affected by salinity and nitrogen source. Phys. Plant 1997, 99, 546-553. [CrossRef]

19. Lincoln, S.D.; Black, B. Halogeton poisoning in range cattle. J. Am. Vet. Med. Assoc. 1980, 176, 717-718. [PubMed]

20. Palaniswamy, U.R.; Bibble, B.B.; McAvoy, R.J. Oxalic acid concentration in purslane (Portulaca oleracea L.) is altered by the stage of harvest and the nitrate to ammonium ratios in hydroponics. Sci. Hortic. 2004, 102, 267-275. [CrossRef]

21. Carvalho, I.S.; Teixaira, M.; Brodelius, M. Effect of salt stress on purslane and potential health benefits: Oxalic acid and fatty acids profile. Proc. Int. Plant Nut. Coll. XVI 2009. Available online: https: //escholarship.org/uc/item/4cc78714 (accessed on 12 October 2016).

22. Wintermans, J.F.; De Mots, A. Spectrophotometric characteristics of chlorophylls a and $b$ and their pheophytins in ethanol. Biochim. Biophys. Acta 1965, 109, 448-453. [CrossRef]

23. Bradford, M.M. A rapid and sensitive method for the quantitation of microgram quantities of protein utilizing the principle of protein-dye binding. Anal. Biochem. 1976, 72, 248-254. [CrossRef]

24. Lisec, J.; Schauer, N.; Kopka, J.; Willmitzer, L.; Fernie, A.R. Gas chromatography mass spectrometry-based metabolite profiling in plants. Nat. Protoc. 2006, 1, 387-396. [CrossRef]

25. Brychkova, G.; Yarmolinsky, D.; Batushansky, A.; Grishkevich, V.; Khozin-Goldberg, I.; Fait, A.; Amir, R.; Fluhr, R.; Sagi, M. Sulfite oxidase activity is essential for normal sulfur, nitrogen and carbon metabolism in tomato leaves. Plants 2015, 4, 573-605. [CrossRef]

26. R. Development Core Team. R: A Language and Environment for Statistical Computing; R Foundation for Statistical Computing: Vienna, Austria, 2017. Available online: https://www.R-projectorg/ (accessed on 8 July 2019).

27. Gu, Z.; Eils, R.; Schlesner, M. Complex heatmaps reveal patterns and correlations in multidimensional genomic data. Bioinformatics 2016, 32, 2847-2849. [CrossRef]

28. Kassambara, A.; Mundt, F. Factoextra: Extract and Visualize the Results of Multivariate Data Analyses. R Package Version 1.0.5. 2017. Available online: https://rdrr.io/cran/factoextra/ (accessed on 8 August 2018).

29. Covarrubias, J.I.; Pisi, A.; Rombolà, A.D. Evaluation of sustainable management techniques for preventing iron chlorosis in the grapevine. Aust. J. Grape Wine Res. 2014, 20, 149-159. [CrossRef]

30. López-Millán, A.; Morales, F.; Abadía, A.; Abadía, J. Changes induced by Fe deficiency and Fe resupply in the organic acid metabolism of sugar beet (Beta vulgaris) leaves. Phys. Plant 2001, 112, 31-38. [CrossRef] [PubMed]

31. Nilsen, E.; Orcutt, D. Nutrient deficiency stress and plant growth and development. Chapter 3. Salinity stress. In The Physiology of Plants under Stress—Soil and Biotic Factors; John Wiley \& Sons Inc.: Hoboken, NJ, USA, 2000; pp. 43-213.

32. Xu, N.; Zhang, X.; Fan, X.; Han, L.; Zeng, C. Effect of nitrogen source and concentration on growth rate and fatty acid composition of Ellipsioidion SP. (Eustigmatophyta). J. Appl. Phyol. 2001, 13, 463-469. [CrossRef]

33. Jin, R.; Wang, Y.; Liu, R.; Gou, J.; Chan, Z. Physiological and Metabolic Changes of Purslane (Portulaca oleracea L.) in Response to Drought, Heat, and Combined Stresses. Front. Plant Sci. 2016, 6, 1123. [CrossRef]

34. Orthen, B.; Popp, M.; Smirnoff, N. Hydroxyl radical scavenging properties of cyclitols. Proceedings of the Royal Society of Edinburgh B. Biol. Sci. 1994, 2, 269-272.

35. Bohnert, H.J.; Nelson, D.E.; Jensen, R.G. Adaptations to environmental stresses. Plant Cell 1995, 7, $1099-1111$. [CrossRef] [PubMed]

36. Nelson, D.E.; Rammesmayer, G.; Bohnert, H.J. Regulation of cell-specific inositol metabolism and transport in plant salinity tolerance. Plant Cell 1998, 10, 753-764. [CrossRef] [PubMed]

37. Nasir, F.; Batarseh, M.; Abdel-Ghani, A.H.; Jiries, A. Free amino acids content in some halophytes under salinity stress in arid environment, Jordan. Clean Soil Air Water 2010, 38, 592-600. [CrossRef] 
38. Kalamaki, M.S.; Merkouropoulos, G.; Kanellis, A.K. Can ornithine accumulation modulate abiotic stress tolerance n Arabidopsis? Plant Signal. Behav. 2009, 4, 1099-1101. [CrossRef]

39. Muscolo, A.; Junker, A.; Klukas, C.; Weigelt-Fischer, K.; Riewe, D.; Altmann, T. Phenotypic and metabolic responses to drought and salinity of four contrasting lentil accessions. J. Exp. Bot. 2015, 66, 5467-5480. [CrossRef]

40. Yang, C.; Chong, J.; Kim, C.; Li, C.; Shi, D.; Wang, D. Osmotic adjustment and ion balance traits of an alkaline resistant halophyte Kochia sieversiana during adaptation to saline and alkaline conditions. Plant Soil 2007, 76, 263-276. [CrossRef]

41. Smirnoff, N. The function and metabolism of ascorbic acid in plants. Ann. Bot. 1996, 78, 661-669. [CrossRef]

42. Conklin, P.L.; Barth, C. Ascorbic acid, a familiar small molecule intertwined in the response of plants to ozone, pathogens and the onset of senescence. Plant Cell Environ. 2004, 27, 959-970. [CrossRef]

43. Hemavathi, C.P.U.; Akula, N.; Young, K.E.; Chun, S.C.; Kim, D.H.; Park, S.W. Enhanced ascorbic acid accumulation in transgenic potato confers tolerance to various abiotic stresses. Biotechnol. Lett. 2010, 32, 321-330. [CrossRef]

(C) 2020 by the authors. Licensee MDPI, Basel, Switzerland. This article is an open access article distributed under the terms and conditions of the Creative Commons Attribution (CC BY) license (http://creativecommons.org/licenses/by/4.0/). 